\title{
INCIDENCE OF LEISHMANIASIS IN AL BAHA PROVINCE, SAUDI ARABIA: PAST AND PRESENT SITUATION (OBSERVATIONAL AND DESCRIPTIVE STUDY)
} By

\author{
KHAIRY ABDEL HAMID MOHAMMAD ${ }^{1^{\star}}$ AND NABEEL HUSSAIN ALHUSSAINY ${ }^{2}$ \\ Department of Parasitology ${ }^{1}$, Faculty of Medicine, Al-Baha University, Saudi Arabia, \\ ('Al-Azhar University, Egypt) and Department of Medical Microbiology and \\ Parasitology ${ }^{2}$, Faculty of Medicine, King Abdulaziz University, Saudi Arabia
}

Abstract

Cutaneous leishmaniasis (CL) is a worldwide skin protozoan infectious disease. This study evaluated the past and present situation of CL in Al-Baha Province. The incidence of CL patients over a total of $(250,000)$ mid-year population was recorded from January to December in both years of 2012 and 2013. The statistical analyses were carried out with SPSS version 12.0 for windows.

The highest number of patients was in 2012 with 11 cases in this year. $37.5 \%$ of patients aged younger than 15 -year and $62.5 \%$ were older than 15 year. The highest incidence of disease was observed in Almandak Governorate in 2012 (8 over 250,000 mid-year population), and the lowest incidence rate was in Al-Tawlah Governorate in the same year. The disease was observed with the incidence rate over 250,000 mid-year population of 3,3,2,1,1 and 1 for January, May, December, March, June and September 2012 respectively and 3,1, and 1 for June, January and April 2013 respectively. The highest incidence of disease was observed among males, Saudi patient who are resident in Al-Baha in both years of 2012 and 2013.

Keywords: Cutaneous leishmaniasis, Incidence, Al-Baha, Parasites, Saudi Arabia

\section{Introduction}

Leishmaniasis, a major global health and economic issue, comprises a group of diseases caused by the protozoan parasites of the genus Leishmania. Transmission of leishmaniasis to mammals, including humans, requires the bite of female phlebotomine sandflies (Postigo, 2010).

Although estimated to cause the ninth largest disease burden among individual infectious diseases, leishmaniasis is largely ignored in discussions of tropical disease priorities (Hotezetal, 2006). Cutaneous leishmaniasis (CL) is endemic in some countries in the Middle East, on the Mediterranean coast and in central Asia.Barsky1978. The disease was first described in Saudi Arabia by Morsy and Shoura (1973). Then, they published a series on CL in Riyadh the Capital (Morsy, 1975; Morsy and Hawwary, 1974), in Bisha Town, Asir Province (Sebai and Morsy, 1975), Western Region of Saudi Arabia (Abdel-Wahab et al, 1985); treatment (Morsy and Shoura, 1973; Sebai et al,
1075), Hofuf, Eastern Saudi Arabia (Buttiker and Lewis, 1979) as well as CL animal reservoir in El-Kharj District (Morsy and Shoura, 1975). Morsy and al Seghayer (1992) in Riyadh gave a brief notes on sandflies, Abou el-Ela et al. (1995) in Riyadh identified Phlebotomous papatasis as the vector of ZCL, and Morsy et al. (1995) studied the sandflies seasonal and daily activities. On the other hand, Leishmania aethiopica was characterized from rock hyrax, Procavia capensis in Najran and anthroponotic leishmaniasis (ACL) was demonstrated in Jizan Province (Morsy et al, 2002).

The study aimed the reviewing of ZCL in the last two years and to investigate $\mathrm{ZCL}$ status in Al-Baha, southwest parts of Saudi Arabia

\section{Subjects, Material and Methods}

A cross-sectional, observational, descriptive study was performed in Al-Baha Province. Al Bahah (Arabic: الباحة Al Bāha) is the capital of Al Bahah Province nestled between the resorts of Mecca and Abha, Al Baha is 
one of the Kingdom's prime tourist attractions. It enjoys a pleasant climate and is surrounded by more than forty forests, including Raghdan, al Zaraeb and Baidan. Al Baha is the headquarters of the Governor, local councils and branches of governmental departments. Receiving the state's special attention, the city of Al Baha abounds in educational, tourist and health institutions, is considered the capital of the Ghamidi and Zahrani tribes in Saudi Arabia, and most of its inhabitants are from the native tribes. The data from the patients who are included in this study were collected from the primary health care Centers of Al Baha Province (Trevor, 1983).Al Baha to Riyadh the Saudi Arabian Capital is $743.29 \mathrm{mi}$.

The study was conducted from January 2012 to December 2013. A written permission was obtained from the Town Administrative Officials prior to the study. Informed consent was taken from each patient or patient's parents if the patient was less than 12 years old.

The incidence of leishmaniasis patients over a total of $(250,000)$ mid-year population were recorded from January to December over the years 2012 and 2013. After being examined by a physician in the primary health care Centers, the patients provided completed a special questionnaire including age, sex, month, nationality, residency in AlBaha and presumptive diagnosis. The lesion sites were then biopsied to confirm the diagnosis of leishmaniasis. Following fixation in methanol for 20-30 sec, the samples were stained with Giemsa (Morsy, 2013). If Leishmania amastigotes were observed under the microscope, cutaneous leishmaniasis was confirmed and the patient's completed questionnaire was evaluated.

Statistical analysis: Data were computerized and analyzed using descriptive statistics and SPSS for Windows version 16.0.

\section{Results}

A total of 16 new cases over 250,000 midyear populations with CL have been identified during the two years. There was the higher number of cases of CL in year 2012 (11 cases) the incidence rate was 4.4/ 100,000 than in year 2013 (5 cases) the incidence rate was $2 / 100,000$.

The numbers of cases (Fig. 1) in year 2012 were three cases in each of January and May, 2 cases in December and one case for each of March, June and September. In 2013 cases were three in June and one case in each of January and April. The numbers of cases (Fig. 2) were in different geographical areas in year 2012 were 8, 2 and 1 cases in Almandak, Al-Baha and Al-Tawlah respectively, while in year 2013 were 2, 2 and 1 cases in Al-Baha, Al-Tawlah and Almandak respectively. Of 16 patients (Fig. 3) ten cases were males and females. They were (Fig. 4) 14 Saudis and 2 cases immigrant workers, but all were (Fig. 5) residents in Al-Baha Province with age groups (Fig. 6) 15- 44 year old $(62.5 \%)$ and $0-15$ year old $(37.5 \%)$.

Table 1: Number of CL by month in Al-Baha Province.

\begin{tabular}{|l|c|c|}
\hline Months & No. of cases 2012 & No. of cases 2103 \\
\hline January & 3 & 1 \\
\hline February & 0 & 0 \\
\hline March & 1 & 0 \\
\hline April & 0 & 1 \\
\hline May & 3 & 0 \\
\hline June & 1 & 3 \\
\hline July & 0 & 0 \\
\hline August & 0 & 0 \\
\hline September & 1 & 0 \\
\hline October & 0 & 0 \\
\hline November & 0 & 0 \\
\hline December & 2 & 5 \\
\hline Total cases & 11 & \\
\hline
\end{tabular}


Table 2: Changes of CL cases by geographical location in Al-Baha Province.

\begin{tabular}{|l|c|c|}
\hline Sector area & No. of cases 2012 & No. of cases 2103 \\
\hline Al-Baha & 2 & 2 \\
\hline Al-Tawlah & 1 & 2 \\
\hline Almandak & 8 & 0 \\
\hline Alaquiq & 0 & 0 \\
\hline Buljurshy & 0 & 0 \\
\hline Quelwah & 0 & 0 \\
\hline Al-Mukhwah & 0 & 1 \\
\hline Total cases & 11 & 5 \\
\hline
\end{tabular}

Table 3: Number of CL according to patients sex in Al-Baha Province.

\begin{tabular}{|l|c|c|}
\hline Year & Male & Female \\
\hline 2012 & 7 & 4 \\
\hline 2013 & 3 & 2 \\
\hline
\end{tabular}

Table 4: Number of CL according to patients' nationality in Al-Baha Province.

\begin{tabular}{|l|l|l|}
\hline Year & Sex & Non Saudi \\
\hline 2012 & 10 & 1 \\
\hline 2013 & 4 & 1 \\
\hline
\end{tabular}

Table 5: Number of CL according to patients' residency in Al-Baha Province.

\begin{tabular}{|l|c|c|}
\hline Year & Rexident & Non Resident \\
\hline 2012 & 11 & 0 \\
\hline 2013 & 5 & 0 \\
\hline
\end{tabular}

Table 6: CL according to patients ages in Al-Baha Province.

\begin{tabular}{|l|c|c|}
\hline Age groups & 2012 & 2013 \\
\hline $0-14$ years & 4 & 2 \\
\hline $15-44$ & 7 & 3 \\
\hline Total & 11 & 5 \\
\hline
\end{tabular}

\section{Discussion}

CL is a parasitic disease, which is caused by the protozoa of the genus Leishmania; those infecting man are mainly the L. tropica, L. major, L. aethiopica, and L. donovani, $L$. infantum. The infection is transmitted through the small phlebotomine sandflies via the biting of infected human or animal hosts. The clinical characteristics of leishmaniasis depend on interactions of Leishmania parasite's invasiveness, tropism, pathogenicity, and hosts' immune responses (Al-Jaser 2005; El-Beshbishy et al, 2013). CL is widely scattered throughout the world it is endemic in tropical and subtropical regions, as well as also endemic in Kingdom of Saudi Arabia (Morsy, 1996).

The present study data proved that Al-Baha
Province is an endemic area of the cutaneous leishmaniasis. The data from primary health care centers in Al-Baha Province were critically revised and considered. However, some patients with cutaneous leishmaniasis were visitors and treated by physicians out of the province.

Also, since this disease is a self-limited one, some patients might have been cured without any medications (Nateghi-Rostami et al, 2010). Thus, it is possible that the incidence of the disease were underestimated in the present study.

As to, age distribution, $62.5 \%$ of the patients were in age group 15-44 year old and $37.5 \%$ in age group $0-14$ year old and it could be due to lack of information about 
possible ways of transferring the disease. This agreed with Hamadto et al. (2003) in Egyptian CL patients

There was a significant sex difference for the incidence of CL as $62.5 \%$ were males and $37.5 \%$ females. This could be due to the way of dressing among women in Al-Baha Province who spend all time indoors, as well as men normally work outdoors,

This fact agreed with Al-Samarai and AlObaidi (2009) in Iraq and Nazari, (2012) in Iran.

A significant difference for the incidence of cutaneous leishmaniasis among different nationalities showed that $87.5 \%$ of infections among Saudi patients followed by $12.5 \%$ among immigrant workers, but all were resident in Al-Baha. This agreed with Hotez et al. (2012) who considered leishmaniasis particularly cutaneous forms are one of the neglected insect-borne diseases in the Middle East.

As regards the incidence of cutaneous leishmaniasis seasonal distribution, it was high in winter and at the beginning of summer, and relatively low in spring, autumn and early winter. The month distribution of the disease through the province reflects the rural type of the disease, which is more prominent in three governorates Almandak, Al -Baha and Al-Tawlah respectively. This agreed with Merdan et al. (1992) in Egypt Northern Sinai related to reserefvoir activity and Doha and Samy (20100 related to the biononicws of the sandfly vector.

\section{Conclusion}

The outcome results showed that CL is endemic in Al-Baha Province, Kingdom of Saudi Arabia. There must be strategy the control of both the animal reservoir(s) and Phlebotomus species vector.

The Public Health and Veterinary Authorities must pay attention to control of the insect-vector and the animal reservoir(s) to minimize disease transmission. No doubt, the collaboration of other regional health authorizes will have a feedback as the King- dom tranreacted with many immigrant employees

\section{References}

Abdel Wahab, RM, El Garem, AA, Morsy, TA, Essa, MH, 1985: The histopathological picture of cutaneous leishmaniasis in western part of Saudi Arabia. J. Egypt. Soc. Parasitol. 15, 2:381-6.

Abou el-Ela, RG, Morsy, TA, Rifaat, MM, al Dakhil, MA, 1995: Morphological studies on Phlebotomus papatasi (Scopoli) in Riyadh City, Saudi Arabia. J. Egypt. Soc. Parasitol. 25, 3:63148.

Al-Jaser, MH, 2005: Treatment trends of cutaneous leishmaniasis in Saudi Arabia. Saudi Med. J. 26:1220-4.

Al-Samarai, AM, Al-Obaidi, HS, 2009: Cutaneous leishmaniasis in Iraq. J. Infect. Develop. Count. 3, 2:123-9.

Buttiker, W, Lewis DJ, 1979: Ecological studies at Hofuf, Eastern Saudi Arabia, in relation to dermal leishmaniasis. Tropenmed. Parasitol. 30:220-9

Doha, SA, Samy, AM, 2010: Bionomics of phlebotomine sand flies (Diptera: Psychodidae) in the province of Al-Baha, Saudi Arabia. Mem. Inst. Oswaldo Cruz. 105, 7:850-6.

El-Beshbishy, HA, Al-Ali, KH, El-Badry, AA, 2013: Molecular characterization of Leishmania infection in sand flies from Al-Madinah AlMunawarah province, western Saudi Arabia. Exp. Parasitol. 134, 2:211-5

Hamadto, HA, EI Fakahany, AF, Morsy, TA, Farrag, AB, Abdel Maksoud, MK, 2003: Reevaluation of zoonotic cutaneous leishmaniasis status in North Sinai Governorate, Egypt. J. Egypt. Soc. Parasitol. 33, 3:687-94

Hotez, PJ, Savioli L, Fenwick A, 2012. Neglected tropical diseases of the Middle East and North Africa: review of their prevalence, distribution and opportunities for control. PLoSNegl Trop Dis 6, e1475.

Merdan, AI, Morsy, TA, Shoukry, A, Wahba, MM, 1992: Two successive years studies on Phlebotomus papatasi in North Sinai Governorate, Egypt. J. Egypt. Soc. Parasitol. 22, 1:91100

Morsy, TA, 1975: Oriental sore in Riyadh, Saudi Arabia. Castellania Tropenmed. Dermatol. 3, 8:155-7, Berlin.

Morsy, TA, 1996: Cutaneous leishmaniasis in 
Egypt: Review and comment. J. Egypt. Soc. Parasitol. 26, 1:105-30

Morsy, TA, 2013: Cutaneous leishmaniasis predisposing to human skin cancer: forty years local and regional studies. J. Egypt. Soc. Parasitol. 43, 3:629-48.

Morsy, TA, Abou el-Ela, RG, Rifaat, MM, al Dakhil, MA, 1995: The seasonal and daily activities of Phlebotomus papatasi in Riyadh, Saudi Arabia. J. Egypt. Soc. Parasitol. 25, 3:699711.

Morsy, TA, al Dakhil, MA, el Bahrawy, AF, 1997: Characterization of Leishmania aethiopica from rock hyrax, Procavia capensis trapped in Najran, Saudi Arabia. J. Egypt. Soc. Parasitol. 27, 2:349-53.

Morsy, TA, al Seghayer, SM, 1992: A brief note on phlebotomine sandflies in Riyadh, Saudi Arabia. J. Egypt. Soc. Parasitol. 22, 2:437-40

Morsy, TA, Essa, TM, Ramadan, NI, 2002: A woman and her son with abnormal complicated anthrponotic cutaneous leishmaniasis. J. Egypt. Soc. Parasitol. 32, 3:767-74.

Morsy, TA, Hawwary, GhH, 1974: Leishmanin skin tests in Riyadh, Saudi Arabia. J. Kwt. Med. Assoc. 8, 3:169-71, Kuwait

Morsy, TA, Shoura, MI, 1973: Some aspects of cutaneous leishmaniasis in Riyadh, Saudi Arabia. The $9^{\text {th }}$ Int. Cong. Trop. Med. Malar. October 14-21; Athens, Greece.
Morsy, TA, Shoura, MI, 1974: Treatment of Saudi Arabian cutaneous lei-shmaniasis. J. Trop. Med. Hyg. 77, 3:68.

Morsy, TA, Shoura, MI, 1975: Natural Leishmania infection sought in animals in El-Kharj, Saudi Arabia. J. Egypt. Pub. Hlth. Assoc. 50, 5:328-31.

Nateghi Rostami M, Keshavarz, H, Edalat, R, Sarrafnejad, A, Shahrestani, T, 2010: CD $8+T$ cells as a source of IFN- $\gamma$ production in human cutaneous leishmaniasis. PLoS Negl Trop Dis. 2010 Oct 12;4(10):e845.

Nazari M. 2012. Cutaneous leishmaniasis in Hamadan, Iran (2004-2010) Persian. Zahedan J. Res. Med. Sci. 13, 9:39-42.

Postigo JA, 2010: Leishmaniasis in the WHO Eastern Mediterranean Region. Int. J. Antimicrob. Agents 36:S62-5.

Sebai, ZA, Morsy, TA, 1975: Cutaneous leishmaniasis in Bisha Town, Saudi Arabia. J. Trop. Med. Hyg. 79, 4:89-91.

Sebai, ZA, Morsy, TA, Suroor, FD, 1975: Treatment of cutaneous leishmaniasis with sodium stibogluconate (Pentostam). J. Egypt. Pub. Hlth. Assoc. 50, 1:59-62

Trevor, M, 1983: Saudi Arabia- A MEED Practical Guide. London: Middle East Economic Digest. $2^{\text {nd }}$ edition. 

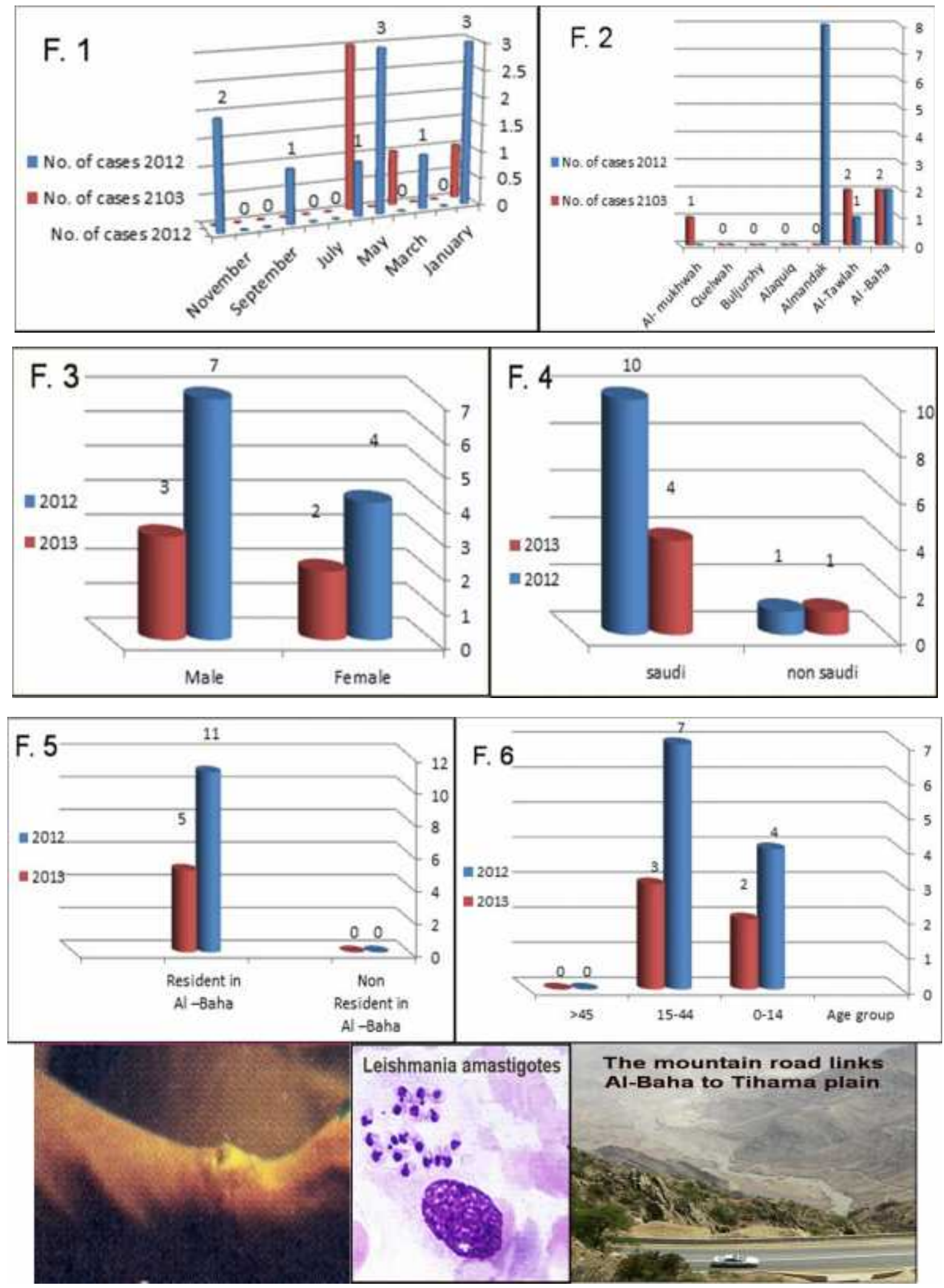